\title{
Detection of Coronary Artery Disease Based on the Calcification Index Obtained by Helical Computed Tomography
}

\author{
Carlos Jader Feldran, Domingos Vtola, Nádia Schiavo \\ Porto Alegre, RS - Brazil
}

\begin{abstract}
Objective - To assess the relation between coronary artery disease and the calcification index on helical computed tomography.

Method - We studied 22 patients (ages ranging from 40 to 70 years) who underwent coronary angiography because of chest pain suggestive of angina pectoris. Findings on coronary angiography were classified as follows: significant obstructive disease (stenosis $\geq 50 \%$ ), nonobstructive disease (stenosis $<50 \%$ ), and no disease. With no previous knowledge of the results of the coronary angiography and within 7 days, helical computed tomography of the chest was performed. Then, data of the coronary angiography were correlated with the calcification index obtained by helical computed tomography.
\end{abstract}

Results - The sensitivity of helical computed tomography to the presence of significant obstructive lesions on coronary angiography was $87.5 \%$, specificity was $100 \%$, and negative and positive predictive values were $75 \%$ and $100 \%$, respectively. The mean calcification index was greater in patients with severe coronary lesions, mainly when involvement of 2 or 3 vessels occurred, than that in patients with no coronary artery disease or with nonobstructive coronary artery lesions $(p<0.05)$.

Conclusion - Helical computed tomography is an effective method for detecting and quantifying coronary artery calcification, and it has proved to be sensitive to and specific for the noninvasive diagnosis of coronary arterystenosis.

Keywords - coronary artery disease, coronary arteries, calcification, computed tomography

Instituto de Cardiologia do Rio Grande do Sul - Fundação Universitária de Cardiologia

Mailing address: Carlos Jader Feldman - Unidade de Pesquisa do IC/FUC - Av. Princesa Isabel, 395 - 90620-001 - Porto Alegre, RS, Brazil

English version by Stela Maris C. Gandour
Coronary artery disease is one of the major causes of morbidity and mortality in industrialized nations. Frequently, acute myocardial infarction or sudden death is the first clinical manifestation of coronary artery disease ${ }^{1}$.

Calcification in the intima of coronary arteries results from atherosclerosis and advanced coronary artery disease ${ }^{2-6}$. Postmortem studies have shown a correlation between extensive calcification of coronary arteries and the severity of coronary stenoses, as well as the frequency of acute myocardial infarction ${ }^{7}$, even though the occurrence of the latter is strongly related to the lipid content of the atherosclerotic plaque ${ }^{8}$. Segments of arteries with large calcifications had a greater number of atherosclerotic plaques than those segments with fewer calcifications ${ }^{1}$. Survival has been shown to be lower in patients with recognized coronary artery disease and calcifications ${ }^{9}$. Other studies ${ }^{10,11}$ have suggested that patients with calcifications in coronary arteries and who undergo thoracotomy have a high incidence of complications.

Early diagnosis and changes in several risk factors are essential elements for reducing mortality or morbidity, or both, in coronary artery disease. However, the early diagnosis and prevention of atherosclerotic coronary artery disease are rendered difficult by the low performance of noninvasive methods for detecting the disease, mainly in young asymptomatic patients ${ }^{13}$. In these patients, early intervention and changes in the risk factors have great value. In many patients with early lesions or still in an asymptomatic phase, stenoses may not be detected ${ }^{14}$, showing that calcium detection in coronary arteries is an important predictor of coronary artery disease, mainly in young patients ${ }^{9}$. Therefore, it is important to explore the potential of new techniques for better detecting and quantifying calcifications in coronary arteries ${ }^{15}$.

Several imaging techniques, such as fluoroscopy, intravascular echography, conventional computed tomography, electron-beam computed tomography, helical computed tomography, and ultrafast computed tomography are 
used for detecting calcification in coronary arteries ${ }^{2,16,17}$. Fluoroscopy has been used for more than 30 years for identifying patients with coronary artery disease ${ }^{2,9,18}$. Intravascular echography has a greater accuracy for detecting atherosclerosis in an early stage; it is, however, an invasive procedure ${ }^{2}$. Digital fluoroscopy and conventional computed tomography have a greater sensitivity than conventional fluoroscopy for detecting calcifications in coronary arteries. Calcium quantification, however, has not been performed with these methods ${ }^{15}$. Computed tomography has a higher sensitivity than fluoroscopy for detecting calcification and allows quantifying calcium deposits. In a study by Agatston et al ${ }^{15}$, the sensitivity of ultrafast computed tomography was $96 \%$ and that of fluoroscopy was $57 \%$, and this method did not detect moderate calcifications. Another disadvantage of fluoroscopy is dependence on the examiner's observation, who should be a physician, and the results are related to this professional's experience. Ultrafast computed tomography has high-resolution contrast, a rapid image acquisition, and allows elimination of the image blurring due to heart movement ${ }^{4,15}$, resulting in a high sensitivity for detecting calcium in coronary arteries. Quantifying this calcium may be useful in determining the degree of coronary artery disease. Therefore, and because ultrafast computed tomography is a noninvasive method, it could play an important role in detection of the disease ${ }^{4}$.

In regard to the use of helical computed tomography for this end, data in the literature are scarce, and no study has been carried out in Brazil. This motivated the present study.

\section{Methods}

We studied 22 patients, $18(81.8 \%)$ males and $4(18.2 \%)$ females, with ages ranging from 40 and 70 years (mean of $59.6 \pm 9$ years). They underwent coronary angiography because of chest pain suggestive of angina pectoris. In a blinded study, i.e., without previous knowledge of the results of the coronary angiography, the patients underwent tomographic assessment. The mean time interval between coronary angiography and helical computed tomography was $3.4 \pm 2.3$ days (ranging from 0 to 7 days), and one patient underwent helical computed tomography one day prior to coronary angiography. Women of childbearing age were excluded from the study.

Helical computed tomography was performed with the use of a helical scanner with a double layer of detectors, and the images were obtained without contrast medium injection. Time of exposure was 1 second for 2 contiguous sections of $2.5 \mathrm{~mm}$ and ranged from 15 to 22 seconds for the whole region of interest. The test was performed during an unforced maintained inspiration. The effective thickness of the sections was $3.2 \mathrm{~mm}$ with an increment of $3 \mathrm{~mm}$. The total duration of the procedure was 10 minutes.

For calculating the calcification index, 20 more cephalic contiguous sections were selected, the first being at the level of the first visible portion of the trunk or of the anterior descending artery of the left coronary artery. This allowed a 6-cm coverage of the coronary arteries measured in the longitudinal axis of the patient.

The presence and extension of coronary calcification were determined in each 20 contiguous sections. A calcified lesion was defined as an area inside the coronary artery, whose tomographic density was above 90 Hounsfield units (HU), covering an area $\geq 0.5 \mathrm{~mm}^{2}$. The images were revised section by section in a work station, using an automatic program (Escore Cardíaco-Elscint, Israel), in which all pixels were counted with numbers greater than the determined threshold.

The region of interest was demarcated around each lesion (fig. 1) and calculations of the area of the lesion, its tomographic density and score were performed with the program Escore Cardíaco (Elscint, Israel). We obtained scores according to those employed by Shemesh et $\mathrm{al}^{2}$ using a minimum threshold of $90 \mathrm{HU}$. Attenuating factors were determined using the following criteria: factor $1=90-199 \mathrm{HU}$; factor $2=200-299 \mathrm{HU}$; factor $3=300-399 \mathrm{HU}$; factor $4=$ $\geq 400 \mathrm{HU}$. A score for each region of interest was calculated by multiplying the attenuating factor by the area. The total calcification index was determined by adding the scores of the 20 sections.

Coronary angiography was performed according to the technique of Judkins, with multiple oblique projections. Stenoses in the main epicardial coronary arteries were measured with a computed technique and analyzed by two experienced hemodynamics professionals. The coronary angiographic findings were classified as follows: no disease (when no coronary artery lesion existed), significant obstructive disease (when the lesion occupied $50 \%$ or more of the arterial diameter of at least one of the major coronary arteries: right coronary artery, anterior descending artery, and circumflex artery), nonobstructive disease (when the stenosis was less than 50\%).

Statistical analysis - Sensitivity, specificity, and predictive values were calculated using the $2 \times 2$ contingency

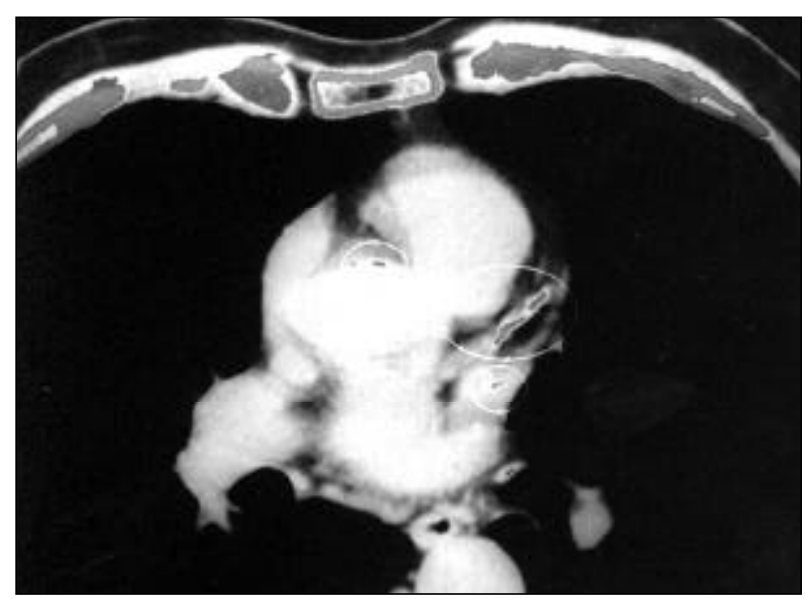

Fig. 1 - Tomographic section showing calcifications in the wall of the ascending aorta and left coronary artery. Note the circles delimiting the lesions for computer reading. 
table. To determine the relation between the calcification index and the degree of coronary artery disease, as well as the number of vessels impaired on coronary angiography, we used mean \pm standard deviation of the scores obtained by the program. We used the chi-square test and the $t$ test for comparing data. $P$ values $<0.05$ were considered significant.

\section{Results}

The cause of hospital admission was acute myocardial infarction in $41 \%$ of the patients and unstable angina in $59 \%$. The presence of one or more risk factors was observed in $86.4 \%$ of the patients, $68.2 \%$ of them having two or more risk factors, as follows: systemic hypertension (54.5\%), smoking $(50.0 \%)$, dyslipidemia (50.0\%), a family history of early atherosclerosis [before 55 years of age (36.4\%)], and diabetes mellitus (13.6\%). One (4.5\%) patient had already undergone myocardial revascularization surgery, and 3 (13.6\%) patients had undergone coronary angioplasty. Six (27.3\%) patients had a previous history of acute myocardial infarction.

Coronary artery disease was angiographically detected in $18(82 \%)$ patients. Out of these patients, $16(88.9 \%)$ had significant obstructive lesions (stenosis $\geq 50 \%$ in at least one of the major coronary arteries), and $2(11.1 \%)$ patients had nonobstructive disease (stenosis $<50 \%$ ). Among the patients with significant obstructive lesions, $8(50 \%)$ had stenosis in 3 vessels, 3 (18.8\%) patients had it in 2 vessels, and $5(31.2 \%)$ patients had it in one vessel. The anterior descending artery was impaired in $17(94.5 \%)$ patients, the circumflex artery in $10(55.5 \%)$ patients, and the right coronary artery in $9(50 \%)$ patients. Four $(18.2 \%)$ patients had normal coronary arteries on coronary angiography.

Coronary artery calcification was found in 14 (63.6\%) patients (figs. 2 and 3). Tables I and II show the association between the presence of calcification on helical computed tomography and the presence and degree of coronary artery disease on coronary angiography.

For the possibility of the presence of coronary artery

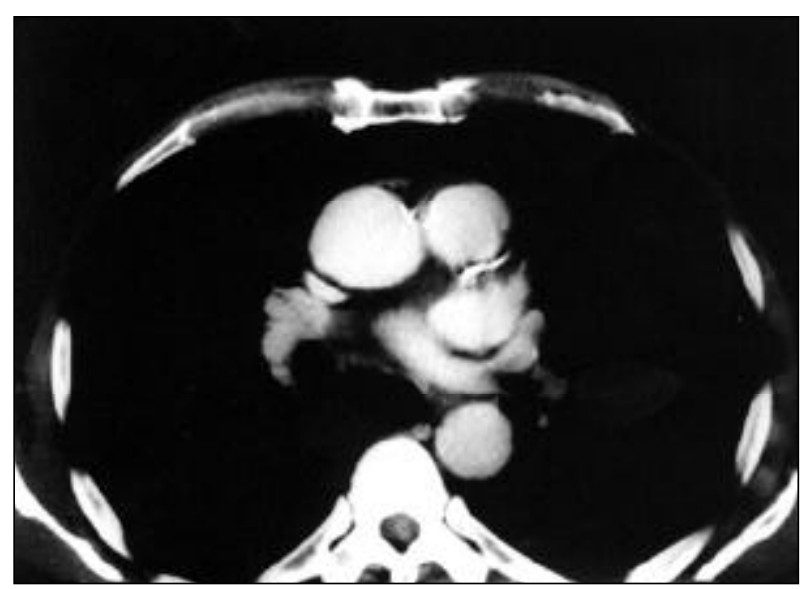

Fig. 2 - Demonstration of calcification in the anterior descending artery in a tomographic section. Calcification is shown as a hyperattenuated area.

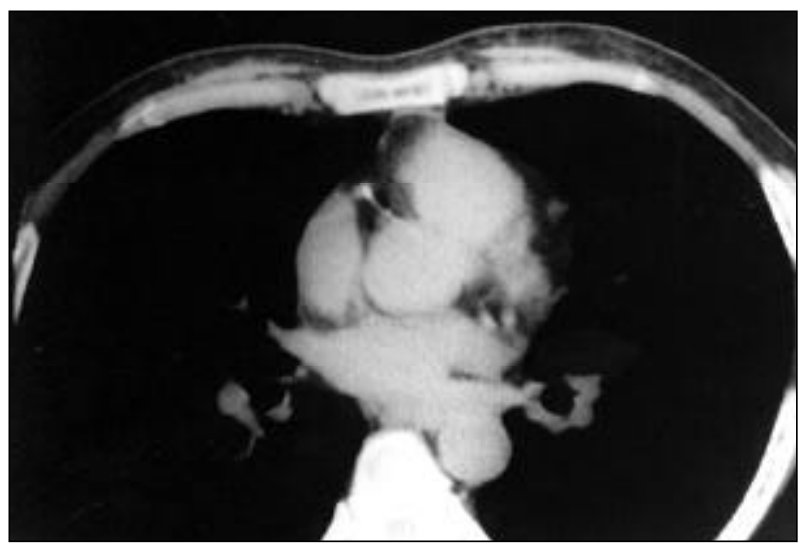

Fig. 3 - Calcification in the right coronary artery shown as an area of greater attenuation in a tomographic section.

\begin{tabular}{|c|c|c|c|c|}
\hline \multicolumn{5}{|c|}{$\begin{array}{l}\text { Table I - Correlation between the frequency of coronary artery } \\
\text { calcification and coronary artery disease }\end{array}$} \\
\hline & & \multicolumn{2}{|c|}{$\begin{array}{l}\text { Coronary artery } \\
\text { disease }\end{array}$} & \multirow[b]{2}{*}{ Total } \\
\hline & & Positive & Negative & \\
\hline \multirow[t]{3}{*}{ Calcification } & Positive & 14 & 0 & 14 \\
\hline & Negative & 4 & 4 & 8 \\
\hline & Total & 18 & 4 & 22 \\
\hline
\end{tabular}

\begin{tabular}{|c|c|c|c|c|c|}
\hline \multicolumn{6}{|c|}{$\begin{array}{c}\text { Table II - Correlation between the presence of calcification and th } \\
\text { degree of coronary artery disease }\end{array}$} \\
\hline & & \multicolumn{3}{|c|}{ Coronary artery disease } & \multirow[b]{2}{*}{ Total } \\
\hline & & Absent & $\begin{array}{c}\text { Non } \\
\text { obstructive }\end{array}$ & $\begin{array}{l}\text { obstructive } \\
\text { Significantly }\end{array}$ & \\
\hline \multirow[t]{3}{*}{ Calcification } & Positive & 0 & 0 & 14 & 14 \\
\hline & Negative & 4 & 2 & 2 & 8 \\
\hline & Total & 4 & 2 & 16 & 22 \\
\hline
\end{tabular}

disease on coronary angiography, the sensitivity of helical computed tomography was $78 \%$ (14 out of 18 patients), and specificity was $100 \%$ ( 4 out of 4 patients). The negative predictive value was $50 \%$, and the positive predictive value was $100 \%$. Out of the 18 patients with positive findings on coronary angiography, 14 (77.8\%) showed calcification on helical computed tomography. In two patients who did not show calcification, atherosclerotic disease was present in one single vessel. In all patients in whom coronary angiography showed nonobstructive disease or absence of coronary lesions, helical computed tomography also detected no calcification. When the population studied was restricted to patients with significant obstructive disease, sensitivity was $87.5 \%$ (14 out of 16 patients), and the negative predictive value was $75 \%$. Specificity and positive predictive value remained $100 \%$. Out of the 14 patients with positive findings on helical computed tomography, 13 (92.8\%) had calcification in the anterior descending artery, $7(50 \%)$ patients in the circumflex artery, and 2(14.3\%) patients in the right coronary artery. Sensitivity for detecting calcification on helical com- 
puted tomography in the anterior descending artery, in the circumflex artery, and in the right coronary artery was $70 \%$, $63 \%$, and $22 \%$, respectively, and specificity was $80 \%, 100 \%$, and $100 \%$, respectively.

Figure 4 shows the mean of the coronary artery calcification indices on coronary angiography of patients without coronary artery lesions, of patients with nonobstructive disease, and of patients with significant obstructive disease.

Figure 5 shows the mean of the calcification indices in relation to the number of coronary arteries impaired on coronary angiography. When only one coronary artery had a lesion or the coronary arteries were normal, the mean of calcification was $18.5 \pm 43.6$, and when 2 or 3 vessels were impaired, the mean of calcification was $78.3 \pm 75.7$, the difference being statistically significant $(\mathrm{p}<0.05)$.

\section{Discussion}

Calcification of coronary arteries has been easily and noninvasively identified and quantified on ultrafast, electron-beam, and helical computed tomography ${ }^{16}$. Most of the published studies have shown sensitivity and specificity of ultrafast computed tomography in relation to the presence of coronary artery disease. The sensitivity of the examination ranged from 88 to $100 \%$ and specificity ranged from 43 to $100 \%{ }^{5,6,15}$. A review of several studies has suggested that electron-beam computed tomography has a

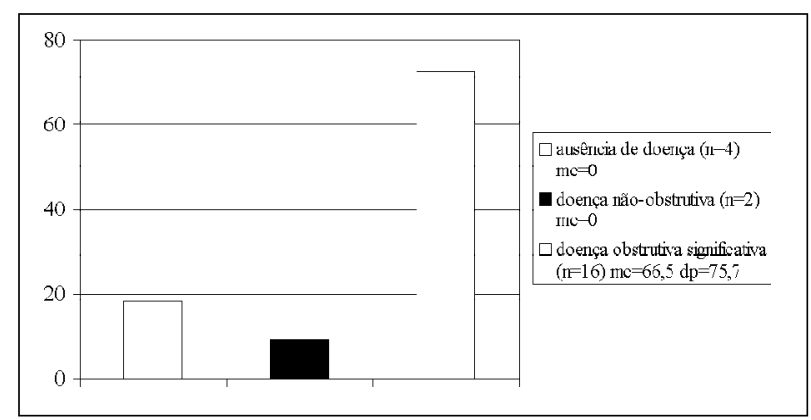

Fig. 4 - Percentage of patients in regard to presence or absence of coronary artery disease and the mean calcification index. $\mathrm{n}$ - number of patients; mc - mean calcification; sd - standard deviation

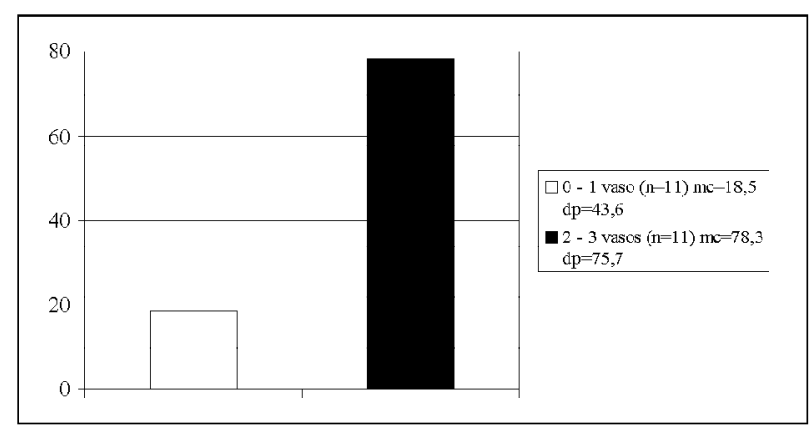

Fig. 5 - Mean calcification index (MC) according to the number of severely impaired coronary arteries. $n$ - number of patients; sd - standard deviation. sensitivity ranging from 80 to $100 \%$ and specificity from 47 to $62 \%{ }^{19}$.

Age and the degree of coronary artery disease influence the values of sensitivity and specificity. Sensitivity increases with the increase in age; specificity, however, decreases ${ }^{14}$. The amount of calcium and the number of coronary artery lesions increase with age, but calcification may be independent from the presence or absence of coronary artery disease ${ }^{15}$.

Janowitz et $\mathrm{al}^{3}$ analyzed the evolution of the amount of calcium in atherosclerotic plaques obtained by ultrafast computed tomography in patients with and without coronary artery disease. Ninety-eight percent of the calcium deposits identified in a first examination were confirmed on following examinations, and a significant increase was observed in the calcification volume and in the total calcified area of the atherosclerotic plaque in the evolution. Patients with coronary artery disease have a large amount of new calcium deposits, which are not found in asymptomatic patients. In patients with no evidence of calcification, both in the first approach and later, the prevalence of ischemic heart disease is extremely low ${ }^{1,5}$.

Coronary artery calcification is more prevalent in males than in females, particularly in younger ones. This difference decreases as age increases, being parallel to the clinical manifestations of coronary artery disease. This happens because females are protected against atherosclerosis before menopause due to the female hormones ${ }^{4}$.

In several studies, the relation between the presence of coronary artery disease detected on coronary angiography and the calcification index obtained by computed tomography is high. Prevalence has ranged from $88 \%$ to $100 \%{ }^{2,6,7,14}$. Calcifications occur more frequently in the proximal portion of the arteries (around $3 \mathrm{~cm})^{2}$. Large amounts of calcium in the plaques are correlated with severe stenoses ${ }^{4}$.

Calcifications found on ultrafast computed tomography usually indicate coronary artery disease, mainly in younger patients in whom calcification of the arteries is not common $^{4}$.

In our study, 14 out of 18 patients with coronary artery disease showed coronary artery calcification on helical computed tomography, comprising a sensitivity of $78 \%$. Specificity and the positive predictive value were $100 \%$, as all patients with no coronary artery disease also had no calcification on helical computed tomography. The negative predictive value was $50 \%$ as 4 out of 8 patients in whom no calcification was detected had coronary artery disease on coronary angiography. This happened to lesions in the right coronary artery, where a certain technical difficulty still exists regarding evaluation of the presence of calcium in its topography.

We observed a lower sensitivity (78\%) for finding coronary artery calcification on helical computed tomography in patients with coronary artery disease than Shemesh et al ${ }^{2}$ (92\%) did. However, our study showed a higher specificity (100\% vs $73 \%)$. In the group of patients with significant obstructive disease, sensitivity was similar (87.5\% vs $91 \%)$, but specificity was higher (100\% vs $52 \%)$. 
In addition to the possibility of detecting the presence or absence of coronary artery disease through a noninvasive method, such as helical computed tomography, analysis of the mean calcification may also differentiate patients with lesions in a single coronary artery from those with disease in 2 or 3 coronary arteries. This is in accordance with a study that employed a methodology similar to ours ${ }^{2}$.
In conclusion, helical computed tomography may be employed as a noninvasive method for detecting coronary artery disease with a high index of sensitivity and specificity. It may also differentiate patients with more severe disease from those with lesions in one single coronary artery, showing, however, in these cases, a high index of false negativity mainly for lesions of the right coronary artery.

\section{References}

1. Simons DB, Schwartz RS, Edwards WD, Sheedy PF, Breen JF, Rumberger J. Noninvasive definition of anatomic coronary artery disease by ultrafast computed tomography scanning: a quantitative pathologic comparison study. J Am Coll Cardiol 1992; 20: 1118-26.

2. Shemesh J, Apter S, Rozemman J, et al. Calcification of coronary arteries: detection and quantification with double-helix CT. Radiology 1995; 197: 779-83.

3. Janowitz W R, Agatston S, Viamonte M. Comparison of serial quantiative evaluation of calcified coronary artery plaque by ultrafast computed tomography in persons with and without obstructive coronary artery disease. Am J Cardiol 1991; 68: 1-6.

4. Janowitz WR, Agatston S, Kaplan G, Viamonte M. Differences in prevalence and extent of coronary artery calcium detected by ultrafast computed tomography in assymptomatic men and women. Am J Cardiol 1993; 72: 247-54.

5. Tanenbaum SR, Kondos GT, Veselick KE, Prendergast MR, Brundage BH, Choomka EV. Detection of calcific deposits in coronary arteries by ultrafast computed tomography and correlation with angiography. Am J Cardiol 1989; 63: 870-1.

6. Wong ND, Abrahamson D, Tobis JM, Eisenberg H, Detrano RC. Detection of coronary artery calcium by ultrafast computed tomography and its relation to clinical evidence of coronary artery disease. Am J Cardiol 1994; 73: 223-7.

7. Frink RJ, Archor RWP, Brown AL, Kincaid OW, Brandenburg RO. Significance of calcification of the coronary arteries. Am J Cardiol 1970; 26: 241-7.

8. Thëroux P, Fuster V. Acute coronary syndromes. Unstable angina and non-Qwave myocardial infarction. Circulation 1998; 97: 1195-1206.

9. Margolis JR, Chen JTT, Kong Y, Peter RH, Behar VS, Kisslo JA. The diagnostic and prognostic significance of coronary artery calcification. Radiology 1980; 137: 609-16
10. Schwarts RS. Coronary artery calcification and prognosis: same song, second verse? J Am Coll Cardiol 1994; 24: 359-61.

11. Moore EH, Greenberg RW, Herrick SH, Miller SW, Mcloud TC, Shepard JD. Coronary artery calcification: significance of incidental detection on CT scans. Radiology 1989; 172: 711-6.

12. Roth BJ, Meyer C. Coronary artery calcification at CT as a predictor for cardiac complications of thoracic surgery. J Comp Assist Tomogr 1997; 21: 619-22.

13. Schalant RC, Alexander RW. Diagnosis and management of chronic ischemic heart disease. In:. Hurst's The Heart Arteries Veins. (Ed). $8^{\text {th }}$ Edition. New York: McGraw-Hill, 1994: 1055-82.

14. Breen JF, Sheedy PF, Schwartz RS, et al. Coronary artery calcification detected with ultrafast CT as an indication of coronary artery disease. Radiology 1992; 185: 435-9.

15. Agatston S, Janowitz WR, Hildner FJ,Zusmer NR, Viamonte M, Detrano R. Quantification of coronary artery calcium using ultrafast computed tomography. J Am Coll Cardiol 1990; 15: 827-32.

16. Shemesh J, Sthoh CI, Tenenbaum A, et al. Comparison of coronary calcium in stable angina pectoris and in first acute myiocardial infarction utilizing doublehelical computerized tomography. Am J Cardiol 1998; 81: 271-5.

17. Stanford W, Thompson BH, Weiss RM. Coronary artery calcification: clinical significance and current methods of detection. AJR 1993; 161: 1139-46.

18. Detrano RC, Wong ND, Tang W, et al. Prognostic significance of cinefluoroscopy for coronary calcific deposits in asymptomatic high risk subjects. J Am Coll Cardiol 1994; 24 : 354-8.

19. Detrano R. Current perspectives on coronary calcification: the role of electronbeam computed tomography. J Am Coll Cardiol 1998; 65: 321-5. 